\title{
Uncertainty Analysis in Contact Resistivity Measurements of Crystalline Silicon Solar Cells
}

\author{
Dong-Youn Shin ${ }^{1, \#}$, Sung-Soo Yoo', and Jun-Young Seo'
}

1 Department of Graphic Arts Engineering, Pukyong National University, 365, Sinseon-ro, Nam-gu, Busan, 608-739, South Korea \# Corresponding Author / E-mail: dongyoun.shin@gmail.com, TEL: +82-51-629-6394, FAX: +82-51-629-6388

KEYWORDS: Silicon solar cell, Contact resistivity, Resistance measurement

\begin{abstract}
The achievement of obtaining low contact resistivity between silver electrodes and the emitter layer of a crystalline silicon solar cell has been a constant issue for the silver paste developers in crystalline silicon solar cell industries. However, it has been found that there are factors that significantly distort the accurate characterization of contact resistivity. One group of such factors have been identified to be not related with the physical traits of silver paste nor the size of a crystalline silicon solar cell wafer. These factors include mathematical formulations to calculate contact resistivity, the preparation method for specimens, probing methods, current source settings, and environmental conditions. On the other hand, the other group of such factors are directly related with the formulation method and composition of silver paste, and the size of a crystalline silicon solar cell wafer where specimens for the resistance measurements are prepared. Through this study, the impact of each factor on resistance measurement using a three-point probe method for the calculation of contact resistivity is analyzed.
\end{abstract}

Manuscript received: January 21, 2015 / Revised: April 22, 2015 / Accepted: May 5, 2015

\section{Introduction}

From among the many types of solar cells as the promising alternatives to fossil fuel, ${ }^{1-5}$ crystalline silicon solar cells were forecasted to hold their dominance for the next few decades. To further increase the cell efficiency of a crystalline silicon solar cell, the achievement of obtaining low contact resistivity between silver electrodes and the emitter layer of a crystalline silicon solar cell has been a primary issue for the developers of silver paste and various approaches have been attempted, such as glass frit chemistry, ${ }^{6-9}$ and the formation of nickel silicide using nickel particles or a nickel layer. ${ }^{10,11}$

For the characterization of the contact resistivity of silver electrodes, diverse resistance measurement methods, such as the circular transmission line method (the circular transfer length method and abbreviated as CTLM), ${ }^{12-14}$ the linear transmission line method (the transfer length method and abbreviated as TLM), ${ }^{15,16}$ and the threepoint probe (TPP) method $^{17-19}$ have been introduced. In general, a specimen for CTLM or TLM requires either a set of concentric circular silver electrodes with different gaps or a set of linear silver electrodes with different spacings, respectively. In this sense, the TPP method has a good advantage over CTLM or TLM because a specimen for the TPP method can be directly prepared from a crystalline silicon solar cell, as compared to CTLM or TLM, which need a specially patterned specimen.

Despite all the valuable research that has been conducted on the characterization of contact resistivity using the aforementioned methods, it has been found that, in accordance with our experiences in developing silver paste for a crystalline silicon solar cell, there are some missing points in previous literature on the characterization of contact resistivity. Hence, the measured resistance between silver electrodes exhibited a big standard deviation as well as a high degree of fluctuation, which consequently affected reliable parametric studies. The ambiguity of the resistance measurements of a crystalline silicon solar cell for the calculation of contact resistivity was found to come from several factors, which have not been fully introduced in previous literature on the characterization of contact resistivity. Due to these factors, the measured resistance values of a crystalline silicon solar cell tended to be totally unreliable, so that the entire time and effort put into performing these tedious resistance measurement works became useless.

Therefore, the main subject of this study is to uncloak the factors that affect the resistance measurements of a crystalline silicon solar cell for the calculation of contact resistivity. For this purpose, the first part of this study investigates the factors affecting the resistance 


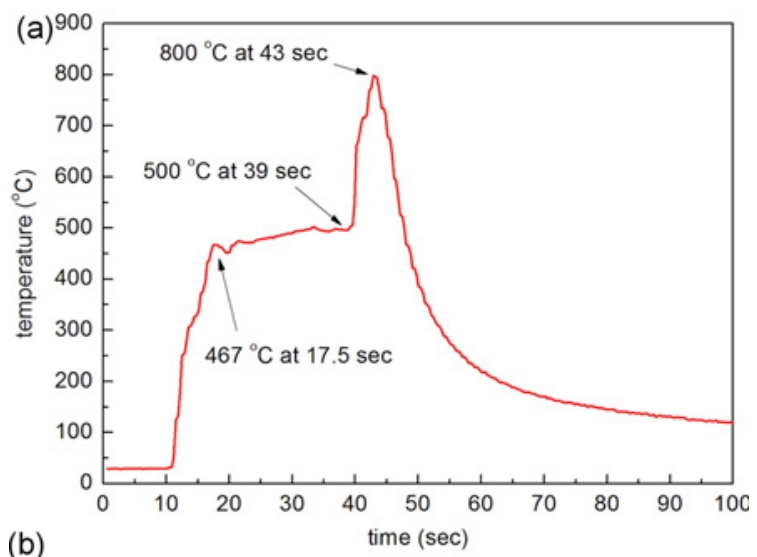

(b)

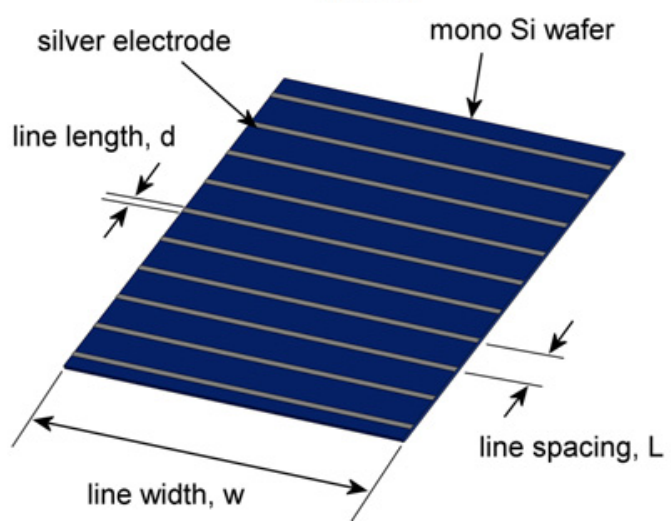

Fig. 1 The used thermal profile in (a) and the configuration of a specimen for the resistance measurements in (b)

measurements of a crystalline silicon solar cell, such as mathematical formulations to calculate contact resistivity, ways to prepare specimens using a laser, probing methods, current source settings, and environmental conditions, which are not directly related to the physical traits of silver paste nor the size of a crystalline silicon solar cell wafer. The second part of this study investigates the factors with relation to the formulation method and composition of silver paste, and the size of a crystalline silicon solar cell wafer where specimens for the resistance measurements of a crystalline silicon solar cell are prepared.

\section{Experimental Details}

The used silver paste consisted of silver particles (Heesung Metal Ltd., Republic of Korea), either HP-0702 (D50 $=0.13 \sim 0.35 \mu \mathrm{m}$ ) or HP-0710 (D50 = 0.9 1.4 $\mu \mathrm{m}$ ); glass frit (V2172, D50 $2.58 \mu \mathrm{m}$, Ceradyne Inc., USA); dispersant (Zephrym PD 2246 SF, Croda International Plc., UK); an organic binder (ethyl cellulose, CAS No. 9004-57-3, Sigma-Aldrich Corp., USA); and a carrier vehicle made with butyl carbitol acetate (2-(2-butoxyethoxy) ethyl acetate, CAS No. 124-17-4, Samchun Pure Chemical Co., Ltd., Republic of Korea), xylene (o-xylene, CAS No. 95-47-6, SK Chemicals Co., Ltd., Republic of Korea) and/or terpineol ( $\alpha$-Terpineol, CAS No. 98-55-5, Kanto Chemical Co., Inc., Japan).

In order to study the factors that affect the resistance measurements of a crystalline silicon solar cell, mono-crystalline silicon wafers with the topmost $\mathrm{SiN}_{\mathrm{x}}$ layer (nominal sheet resistance: $50 \Omega / \mathrm{sq}$, KPE Co., Ltd., Republic of Korea) were either used as supplied at the full length scale of $156 \mathrm{~mm} \times 156 \mathrm{~mm}$, or they were divided into small square pieces at the length scale of $20 \mathrm{~mm} \times 20 \mathrm{~mm}$ using a green laser (Nanio 532-10-V, InnoLas Laser GmbH, Germany), depending on the experimental purposes.

Silver paste was screen-printed onto either full scale crystalline silicon solar cell wafers or small square pieces to form discrete linear silver electrodes at the line spacing of $2 \mathrm{~mm}$. Once the silver paste was screen-printed, specimens were dried on a hot plate stirrer at $110^{\circ} \mathrm{C}$ for 10 min, followed by a second drying on a hot plate (DHSL.HP2020300, DHSL Korea Co., Ltd., Republic of Korea) at $150^{\circ} \mathrm{C}$ for $10 \mathrm{~min}$. Finally, they were subject to rapid thermal sintering at up to $800^{\circ} \mathrm{C}$ using a rapid thermal processor (AccuThermo AW 610, Allwin21 Corp., USA). The used thermal profile is shown in Fig. 1(a).

Once sintered, they were further cut using a green laser to avoid leakage current along their edges, and the specimens for the resistance measurements of a crystalline silicon solar cell were finally completed, as shown in Fig. 1(b). The line width of the specimens, w, eventually lay in the range of $10 \mathrm{~mm}$ to $18 \mathrm{~mm}$. The line length, $\mathrm{d}$, for the silver electrodes was measured with an optical microscope (JSZ-7XT, Samwon Scientific Ind. Co., Ltd., Republic of Korea). Resistance between the silver electrodes was measured with a probe station (MST 4000A, MS Tech Co., Ltd., Republic of Korea) and a source meter (Model 2401, Keithley Instruments Inc., USA). The microscopic images of specimens were taken using a field emission scanning electron microscope (FE-SEM) (JSM-6700F, Jeol Ltd., Japan). For the extraction of contact resistance, $R_{c}$, sheet resistance $R_{s}$, and transfer length, $L_{t}$, from the measured resistance data, Microsoft Excel 2013 was used.

\section{Results and Discussion}

\subsection{The Influence of the Mathematical Formulation on the Calculated Contact Resistivity}

A typical plot of the measured resistance data is shown in Fig. 2(a), where $R_{t}$ in the $y$-axis represents the resistance at any given distance, $\mathrm{L}$, between two silver electrodes along with the x-axis. Through the linear curve fitting using Microsoft Excel 2013, contact resistance, $R_{c}$, sheet resistance $\mathrm{R}_{\mathrm{s}}$, and transfer length, $\mathrm{L}_{\mathrm{t}}$, can be directly extracted using Eqs. (1) and (2) with the given line width, w.

$$
\begin{gathered}
R_{t}=R_{s} / w \times L+2 R_{c} \\
L_{t}=R_{c} /\left(R_{s} / w\right) \quad \text { where } R_{s} / w=m
\end{gathered}
$$

Consequently, contact resistivity is readily calculated from the measured resistance data using Eq. (3), which accounts for the effective contact area due to current crowding. ${ }^{15,20,21}$ Normally, the calculated value of contact resistivity using Eq. (3) has no significant difference from that of contact resistivity using the more rigorous Eq. (4), ${ }^{18,20}$ as shown in the plot with the round symbols from Fig. 2(b), when the contact resistivity is small enough to ensure that the line length of silver electrodes, $\mathrm{d}$, is greater than $1.5 \mathrm{~L}_{\mathrm{t}}$. However, the calculation of contact resistivity using the more rigorous Eq. (4) becomes compulsory in the case where contact resistivity is not small enough or the ratio of $d / L_{t}$ lies between 0.5 and 1.5 , as shown in the plot with square symbols in 
(a)
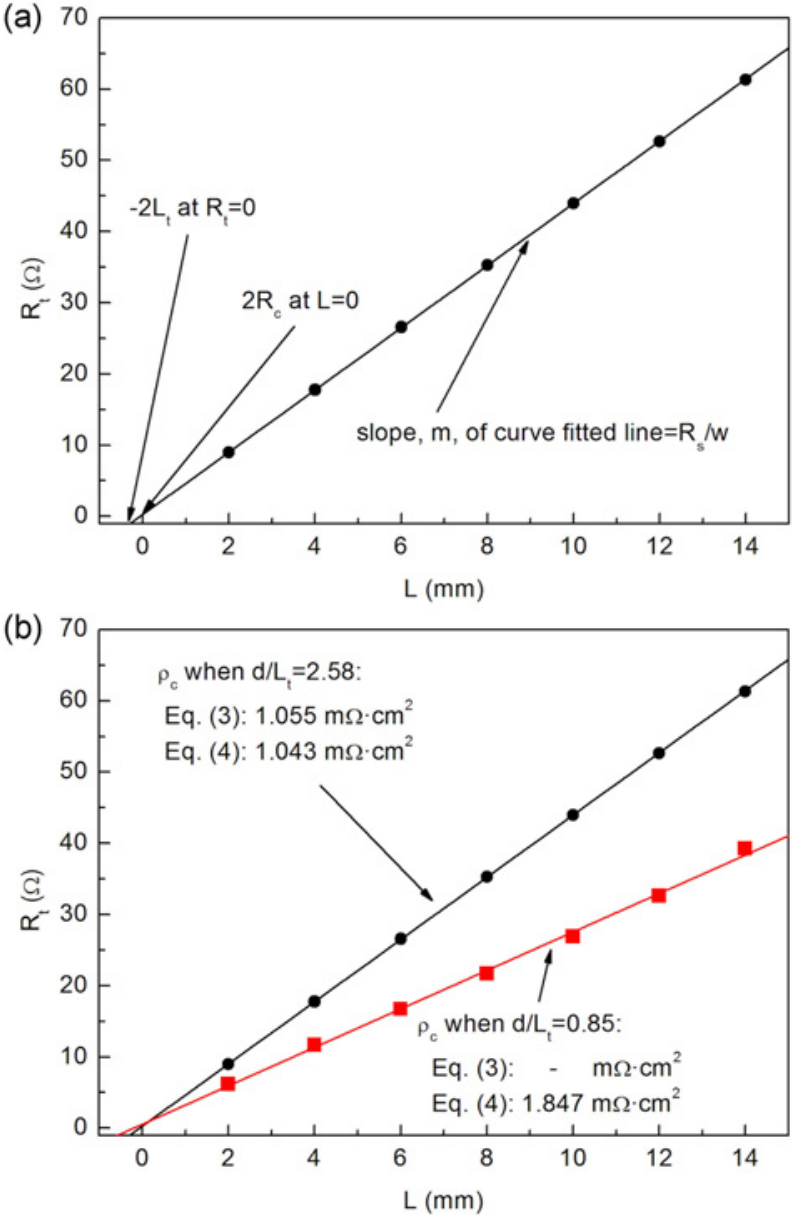

Fig. 2 Typical plot with the measured resistance data in (a) and comparison of contact resistivity values calculated with Eqs. (3) and (4)

Fig. 2(b). Therefore, Eq. (4) is employed for the calculation of contact resistivity all throughout this study.

$$
\begin{gathered}
\rho_{c}=R w L_{t} \text { if } d \geq 1.5 L_{t} \text { or } R_{c} w d \text { if } d \leq 0.5 L_{t} \\
\rho_{c}=R_{c} w\left(L_{t} \tanh \left(d / L_{t}\right)\right)
\end{gathered}
$$

\subsection{The Influence of Specimen Preparation Methods on Resistance Measurements}

It is noteworthy that the sheet resistance of the two plots with round and square symbols in Fig. 2(b) is quite different, even though the way to prepare specimens was identical, except for the way of how the specimens were scribed with a laser. When the specimen was laser scribed on its front side, where silver electrodes were printed, and then broken, its contact resistivity and sheet resistance were $1.847 \mathrm{~m} \Omega \cdot \mathrm{cm}^{2}$ and $26.999 \Omega /$ sq, respectively. On the other hand, the contact resistivity and sheet resistance of the specimen were $1.043 \mathrm{~m} \Omega \cdot \mathrm{cm}^{2}$ and $65.375 \Omega / \mathrm{sq}$, when it was laser scribed on its backside and then broken.

This difference can be elucidated with the development of the edge shunt, which relies on the employed laser scribing direction. As can be seen in Fig. 3(a), the deep penetration of a laser from the front side toward the backside is postulated to melt both silver and silicon, and to eventually develop the strong edge shunt of the specimen, when the
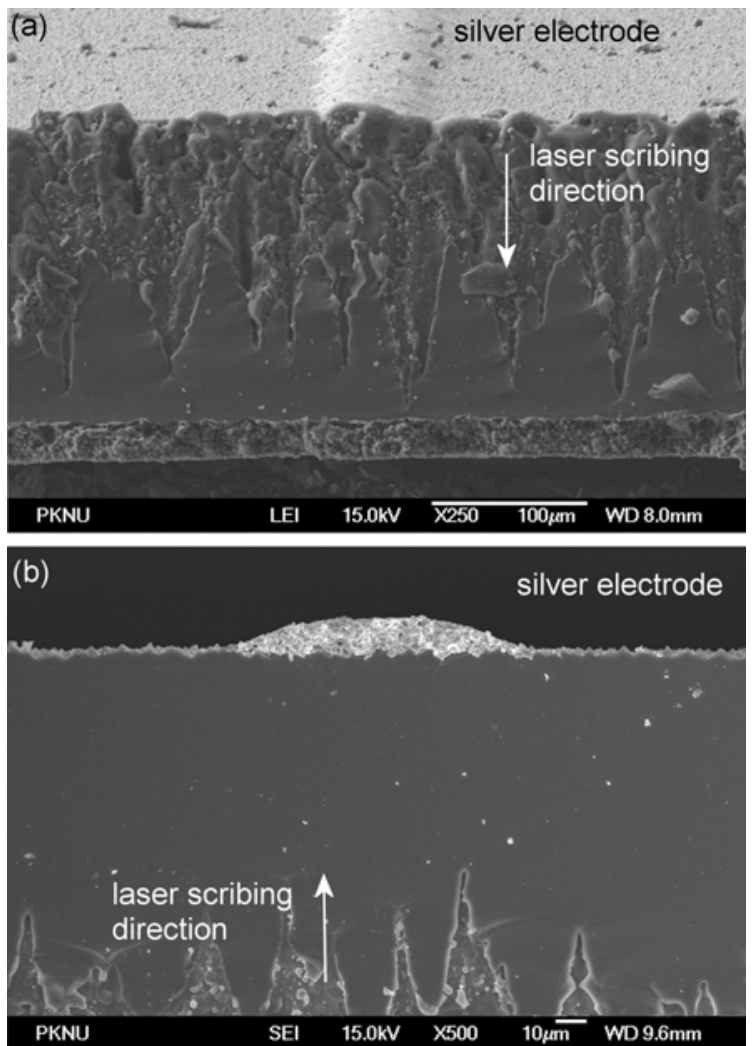

Fig. 3 The edges of the specimens when the laser scribing was conducted on (a) the front side, and (b) the backside

laser scribing was done on the front side of the specimen. As a result, the measured sheet resistance became $26.999 \Omega /$ sq, which was much lower than the calculated sheet resistance of a crystalline silicon solar cell wafer, which was $65.375 \Omega / \mathrm{sq}$. On the other hand, the contact interface between the silver electrode and the emitter layer of a crystalline silicon solar cell remained intact when the laser scribing was conducted on the backside of the specimen, as shown in Fig. 3(b). Therefore, the proper way to eliminate the factor, which disturbs the interpretation of the measured resistance data for the calculation of contact resistivity, should scribe specimens on their backside with a laser.

\subsection{The Influence of Measuring Methods and Conditions on Resistance Measurements}

To investigate the impact of probing methods on resistance measurements, three different probing methods were used on the same specimen. As shown in Fig. 4, method A is a two-point probe method, where one probe for voltage and current high is anchored at the first silver electrode and the other probe for voltage and current low moves sequentially from the second to the last silver electrode. Method B is a modified TLM with four-point probes, ${ }^{16}$ where the first two probes for voltage high and current high, respectively, are anchored at the first electrode and the other two probes for voltage low and current low, respectively, move together sequentially from the second to the last silver electrode. Method C is the TPP method, ${ }^{17-19}$ where the first two probes of voltage high and current high, respectively, are anchored at the first silver electrode, the third probe for current low is anchored at the last silver electrode, and the last probe for voltage low moves sequentially from the second to the last silver electrode. 
(a)

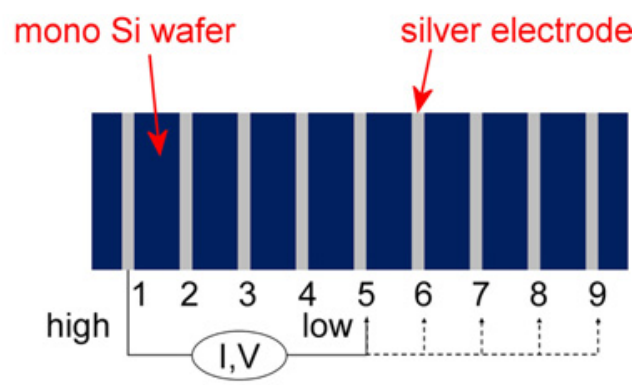

(b)

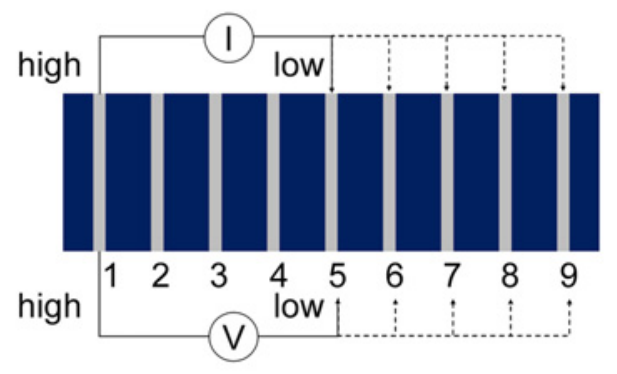

(c)

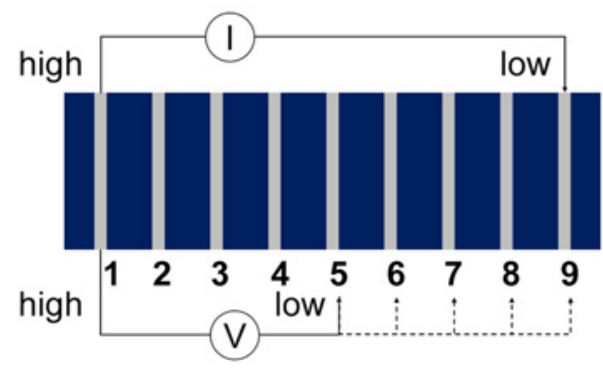

Fig. 4 Comparison of probing methods for resistance measurements, (a) method a, (b) method b, and (c) method c

As can be seen in Fig. 5(a), the contact resistivity measured by method A was found the most inaccurate. The result was $21.612 \pm 0.291 \mathrm{~m} \Omega \mathrm{cm}^{2}$. This is because a two-point probe method suffers from the parasitic resistance induced by the probes themselves. Method C, i.e., the TPP method, was found to produce the most accurate contact resistivity, which was $1.043 \pm 0.048 \mathrm{~m} \Omega \mathrm{cm}^{2}$, as compared to that using method $\mathrm{B}$, which resulted in $3.574 \pm 0.438 \mathrm{~m} \Omega \mathrm{cm}^{2}$.

It was also found that the current source settings of a source meter affected resistance measurements, as shown in Fig. 5(b). The contact resistivity with the current source set in an auto mode was $1.722 \pm 0.007 \mathrm{~m} \Omega \mathrm{cm}^{2}$, which is higher than $1.043 \pm 0.048 \mathrm{~m} \Omega \cdot \mathrm{cm}^{2}$ by $65.1 \%$ with the current source set in a manual mode of $10 \mathrm{~mA}$. This higher contact resistivity in the auto mode was caused by the unwanted automatic change of current from $100 \mathrm{~mA}$ to $10 \mathrm{~mA}$ while the probe moved from the second to the third silver electrode. Therefore, it is necessary to set the current source to the manual mode, because the calculated contact resistivity from the curve fitted line could be greatly influenced by the change of current during resistance measurements. It is simple to find an appropriate current between two high and low current probes anchored at the first and last silver electrodes. First, an arbitrary current is applied between two high and low current probes. Second, the current between two high and low current probes needs to be lowered if the resistance is not measurable when the voltage low probe is placed on the last silver electrode. Otherwise, the current between the two high and low current probes is applicable

Fig. 5(c) shows the impact of environmental conditions, i.e., light (a)

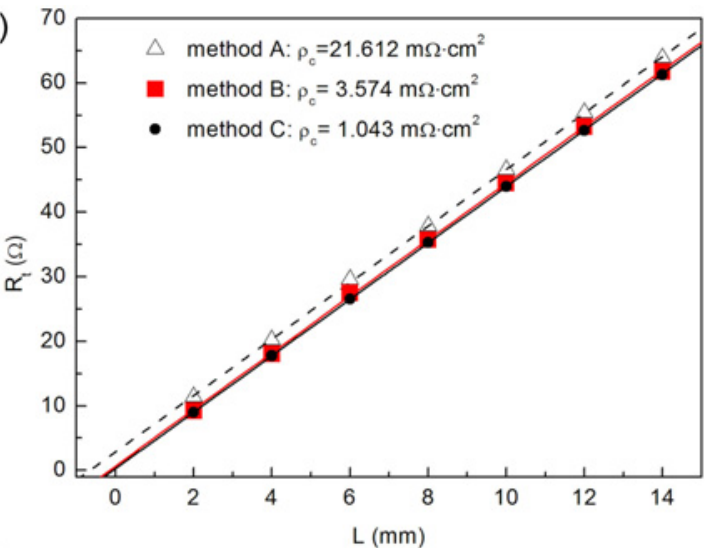

(b)

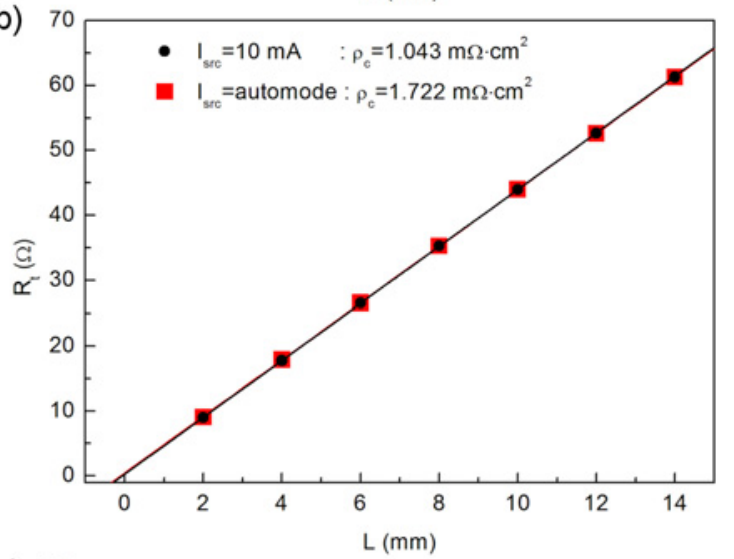

(c)

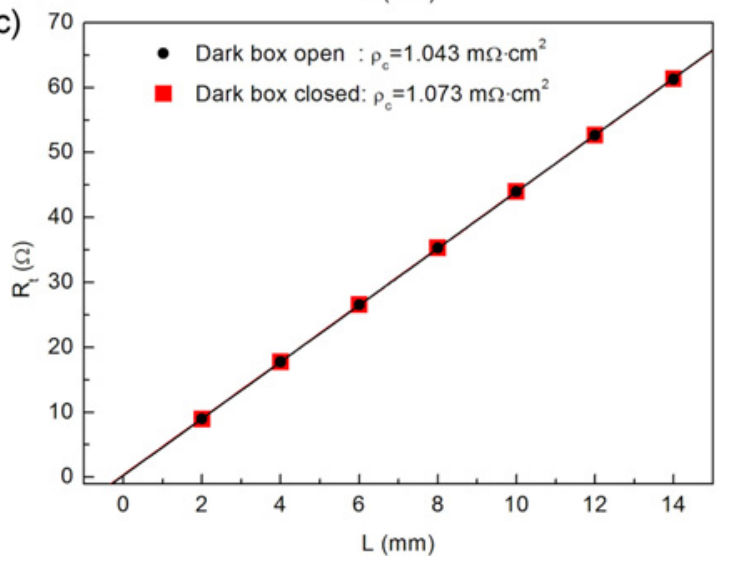

Fig. 5 Comparison of resistance measurements with (a) different probing methods, (b) current source settings, and (c) environmental conditions, such as light illumination

illumination on the resistance measurements of a crystalline silicon solar cell. Because a crystalline silicon solar cell can generate electricity under light illumination, the specimen is said to be kept in the dark while its resistance is measured. However, the calculated contact resistivity under light illumination from a normal fluorescent lamp in an open dark box was $1.043 \pm 0.048 \mathrm{~m} \Omega \cdot \mathrm{cm}^{2}$, which was just slightly below by $-2.796 \%$, as compared to that without light illumination in a closed dark box, which resulted in $1.073 \pm 0.047 \mathrm{~m} \Omega \cdot \mathrm{cm}^{2}$. Therefore, this minute error might be acceptable from the practical viewpoint.

3.4 The Influence of Silver Paste and the Size of a Crystalline Silicon Solar Cell Wafer on Resistance Measurements

Until now, factors affecting resistance measurements with no direct 

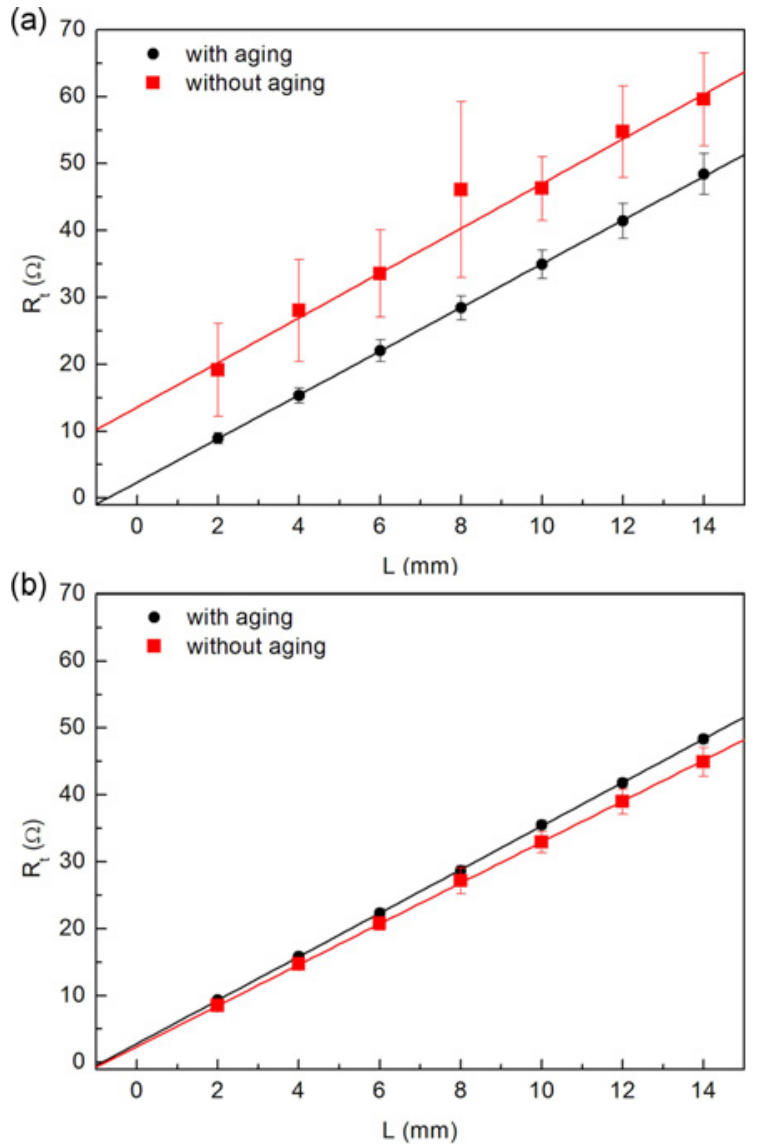

Fig. 6 The influence of aging of silver paste on resistance measurements, consisting of (a) small silver particles (HP-0702, D50 $=0.13 \sim 0.35 \mu \mathrm{m}$ ), and (b) large silver particles (HP-0710, D50 $=0.9 \sim 1.4 \mu \mathrm{m})$

relation to the physical traits of silver paste nor the size of a crystalline silicon solar cell wafer have been discussed. In the case of the specimens used in this study, the most suitable resistance measurement method was found to be the TPP method with the manually set current source of $10 \mathrm{~mA}$. However, there are factors affecting resistance measurements with relation to silver paste as well. They are the aging and particle size of silver paste.

As can be seen in Fig. 6, two types of silver paste with small (HP0702, D50=0.13 0.35 $\mu \mathrm{m}$ ) or large (HP-0710, D50=0.9 1.4 $\mu \mathrm{m})$ silver particles were experimented on, with or without aging for a week. If no aging was conducted, the measured resistance between two silver electrodes, along with the distance, L, exhibited not only a big standard deviation but also a high degree of fluctuation, especially when the used silver particles were small, as shown in Fig. 6(a). It was reported that when dynamic aging was performed using a roll mixer, ${ }^{22}$ the formation of the inter-particle network in the slurries could be greatly prevented by increasing the particle surface coverage with a dispersant. This also explains why the aging of silver paste with large silver particles has less of an impact on resistance measurements, as shown in Fig. 6(b), because large silver particles have less specific surface area. As a result, it can be concluded that silver paste should be aged for a while, because the enhanced dispersion of particulate ingredients, such as silver particles and glass frit, leads to the reduction of the standard deviation and the suppression of fluctuation in resistance measurements.
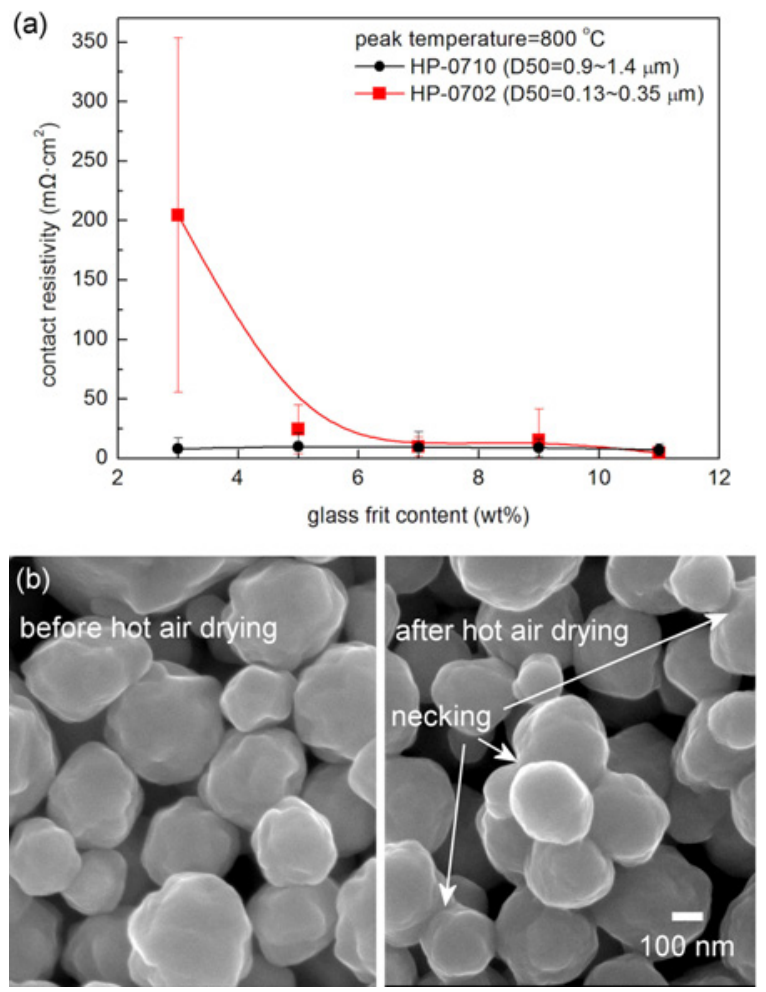

Fig. 7 The influence of silver particle size on contact resistivity along with the solid contents of glass frit in (a) and necking formation of small silver particles, HP-0702 before and after being dried with hot air in (b)

However, it is worth noting that the use of small silver particles has a detrimental effect on not only resistance measurements but also on contact resistivity itself, as compared to the use of large silver particles. As can be seen in Fig. 7(a), the contact resistivity of silver paste with large silver particles remains almost constant all throughout the range of the solid content of glass frit from $3 \mathrm{wt} \%$ to $11 \mathrm{wt} \%$, with respect to the overall solid contents of silver particles and glass frit when the specimens were prepared from small square pieces of $20 \mathrm{~mm} \times 20 \mathrm{~mm}$. On the other hand, the contact resistivity of silver paste with small silver particles notably increased below the glass frit content of $7 \mathrm{wt} \%$, with respect to the overall solid contents of silver particles and glass frit on the specimens that were prepared from small square pieces of $20 \mathrm{~mm} \times 20 \mathrm{~mm}$.

It was reported that the use of extremely small silver particles could lead to a considerable amount of volumetric shrinkage during a high temperature sintering process. This is because of the excessive volume ratio of a dispersant to silver nano-particles. ${ }^{23}$ Therefore, at the first glance, the incomplete contact formation, which results from high residual stress due to the high volumetric shrinkage of the sintered silver electrodes, seems to be responsible for high contact resistivity.

However, if the dispersant layer thickness is assumed $2.5 \mathrm{~nm}$, the volume ratio of a dispersant to silver particles is dramatically dwindled from $107.87 \%$ with the average size of silver particles at $18.1 \mathrm{~nm}$, to $6.38 \%$ with the average size of silver particles at $0.24 \mu \mathrm{m}$, which is close to the average size of silver particles for HP-0702. Therefore, the incomplete contact formation, which is due to high residual stress, might not be the primary reason for high contact resistivity in this case. 
A more plausible postulation needs to be made to explain why the used small silver particles, which are not as extremely small as in the previous literature outlined in the work of Shin et al., ${ }^{23}$ requires the solid content of glass frit to be higher than $7 \mathrm{wt} \%$, as compared to the solid content of glass frit in silver paste with large silver particles.

For the good contact formation between silver electrodes and the emitter layer of a crystalline silicon solar cell, the melt of glass frit should be forced downward to the surface of a crystalline silicon solar cell wafer due to the squeeze of silver particles during their coarsening and densification at the elevated temperature. However, small silver particles of HP-0702 were found to develop necking between them even when dried using hot air from a hand drier, as shown in Fig. 7(b). According to this experimental observation, it can be postulated that the small voids, as well as the early necking formation of small silver particles, impedes the flow of the molten glass frit to the surface of a crystalline silicon solar cell wafer during a high temperature sintering process and hence, the use of small silver particles exhibits sufficiently low contact resistivity only at a high enough solid content of glass frit in silver paste.

The last factor to discuss is the size of a crystalline silicon solar cell wafer where specimens for the resistance measurements were prepared. The contact resistivity looks like it is not affected by the solid content of glass frit when silver electrodes were screen-printed and sintered on small square pieces of $20 \mathrm{~mm} \times 20 \mathrm{~mm}$, in accordance with the experimental results shown in Fig. 8(a), with large silver particles. However, if silver electrodes were screen-printed and sintered on fullscale crystalline silicon solar cell wafers of $156 \mathrm{~mm} \times 156 \mathrm{~mm}$, the contact resistivity and its standard deviation greatly increased. This is postulated to be caused by the stress induced poor contact formation between silver electrodes and the emitter layer of a crystalline silicon solar cell. The bowing of a crystalline silicon solar cell wafer occurs during a high temperature sintering process due to the different thermal expansions of the front and back sides of a crystalline silicon solar cell wafer. This is especially true when aluminum paste is applied on the backside of a crystalline silicon solar cell wafer. While the bowed crystalline silicon solar cell wafer has been cooled, the different thermal contractions of the silver electrodes and crystalline silicon solar cell wafer develop the interfacial stress, which is opposite to the interfacial stress that occurs while a crystalline silicon solar cell wafer is sintered, and eventually weakens the contact between them. This stress induced poor contact formation during the cooling of a crystalline silicon solar cell wafer becomes worse, especially when the size of a crystalline silicon solar cell wafer becomes larger.

This postulation is also partially supported by the change of optimum peak temperature. When the size of a crystalline silicon solar cell wafer was as small as $20 \mathrm{~mm} \times 20 \mathrm{~mm}$, the optimum peak temperature was around $800^{\circ} \mathrm{C}$. However, the optimum peak temperature was shifted down to $780^{\circ} \mathrm{C}$ when the size of a crystalline silicon solar cell wafer was $156 \mathrm{~mm} \times 156 \mathrm{~mm}$. Thanks to the reduced bowing at a lower peak temperature, the interfacial stress between silver electrodes and the emitter layer of a crystalline silicon solar cell was less developed, so that contact resistivity became the lowest at the solid content of glass frit of $11 \mathrm{wt} \%$, as shown in Fig. 8(b).

By establishing adequate resistance measurement protocols on the basis of the findings in this study, the contact resistivity measurement
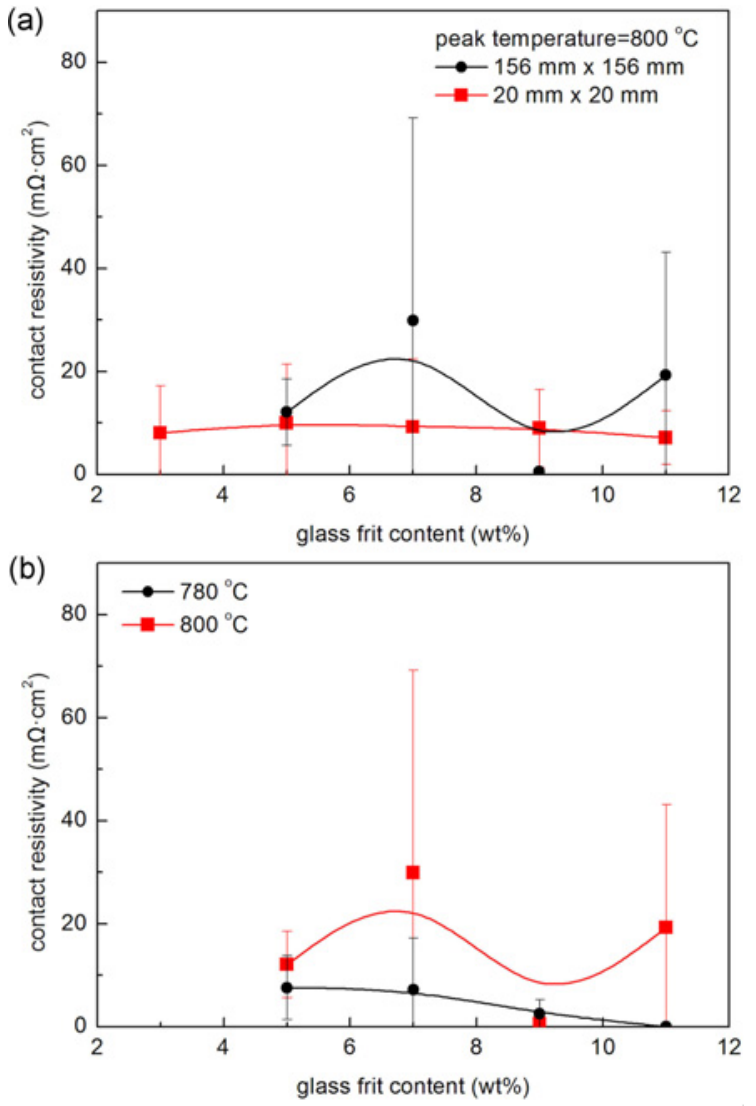

Fig. 8 The influence of the size of a crystalline silicon solar cell wafer on (a) contact resistivity, and (b) optimum peak temperature
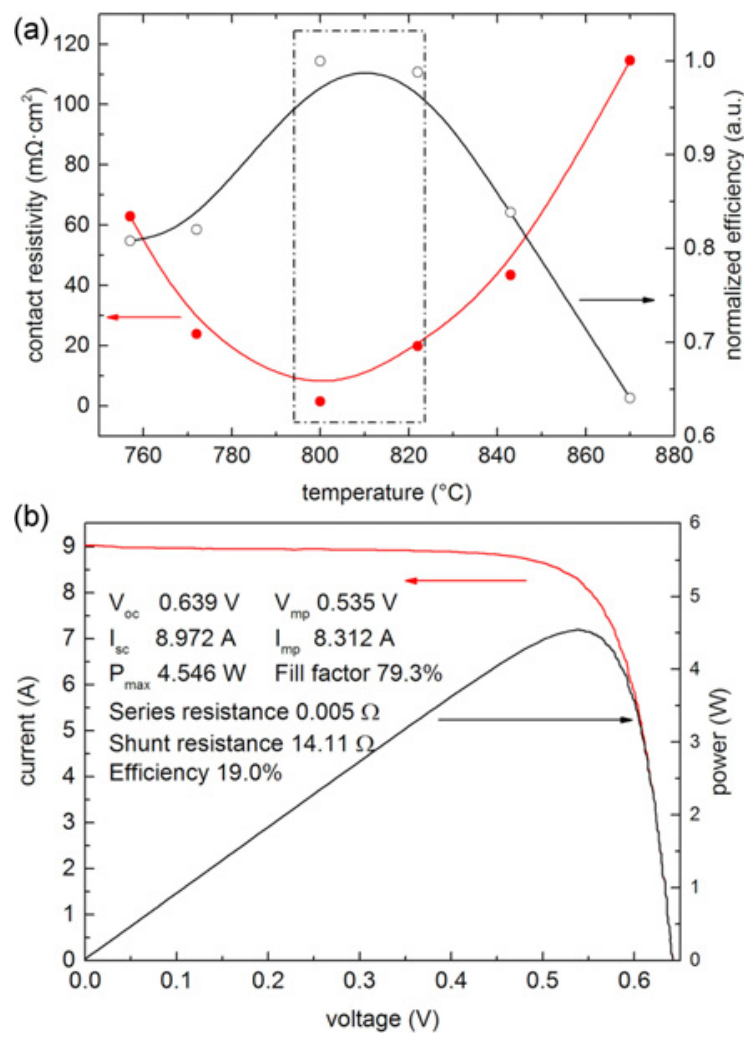

Fig. 9 (a) Correlation between contact resistivity and cell efficiency, and (b) the best cell efficiency achieved with the in-house developed silver paste on a monocrystalline silicon solar cell wafer with $78 \Omega / \mathrm{sq}$ 
Table 1 Comparison of the calculated contact resistivity and sheet resistance with various conditions

\begin{tabular}{|c|c|c|c|c|c|c|c|c|}
\hline \multirow{2}{*}{ Eq. } & \multirow{2}{*}{$\begin{array}{l}\text { Probing } \\
\text { method }\end{array}$} & \multirow{2}{*}{$\begin{array}{c}\text { Laser } \\
\text { scribing side }\end{array}$} & \multirow{2}{*}{$\begin{array}{l}\text { Current source } \\
\text { setting }(\mathrm{mA})\end{array}$} & \multirow{2}{*}{$\begin{array}{l}\text { Dark box } \\
\text { condition }\end{array}$} & \multicolumn{2}{|c|}{ Contact resistivity } & \multicolumn{2}{|c|}{ Sheet resistance } \\
\hline & & & & & $\left(\mathrm{m} \Omega \cdot \mathrm{cm}^{2}\right)$ & Error $(\%)$ & $(\Omega / s q)$ & Error (\%) \\
\hline (3) & $\mathrm{C}$ & back & 10 & open & 1.055 & 1.137 & 65.375 & 0.000 \\
\hline (4) & $\mathrm{C}$ & back & 10 & open & 1.043 & & 65.375 & \\
\hline (4) & A & back & 10 & open & 21.612 & 1972.100 & 65.557 & 0.278 \\
\hline (4) & $\mathrm{B}$ & back & 10 & open & 3.574 & 242.665 & 65.649 & 0.419 \\
\hline (4) & $\mathrm{C}$ & back & 10 & open & 1.043 & & 65.375 & \\
\hline (4) & $\mathrm{C}$ & back & 10 & open & 1.043 & & 65.375 & \\
\hline (4) & $\mathrm{C}$ & back & auto mode & open & 1.722 & 65.101 & 65.219 & -0.239 \\
\hline (4) & $\mathrm{C}$ & back & 10 & open & 1.043 & & 65.375 & \\
\hline (4) & $\mathrm{C}$ & back & 10 & closed & 1.073 & & 65.446 & \\
\hline (4) & $\mathrm{C}$ & back & 10 & open & 1.043 & -2.796 & 65.375 & -0.108 \\
\hline
\end{tabular}

of silver electrodes on a crystalline silicon solar cell wafer became reliable. The optimization of the in-house developed silver paste's compositions as well as co-firing thermal profile was conducted using the established protocols, and $19 \%$ cell efficiency was achieved on a monocrystalline silicon solar cell wafer with the emitter sheet resistance of $78 \Omega /$ sq (E-Ton Solar Tech Co., Ltd., Taiwan), as shown in Fig. 9.

\section{Conclusions}

In this study, factors affecting resistance measurements in a crystalline silicon solar cell have been comparatively and comprehensively analyzed. Factors, which did not originate from the physical traits of silver paste nor the size of a crystalline silicon solar cell wafer, were identified. These factors included mathematical formulations to calculate contact resistivity, the preparation method for specimens, probing methods, current source settings, and environmental conditions. The investigation of probing methods reveals that the TPP method is not only simple but also the most accurate. The second most significant factor was found to be the preparation method for specimens. Laser scribing must be done on the backside of a crystalline silicon solar cell wafer, where no silver electrodes are printed, to evade the edge shunt of the specimen, which severely disturbed the interpretation of the measured resistance data as well as the sheet resistance. The TPP method using Eq. (4) with the manually set current source of $10 \mathrm{~mA}$ was also found to calculate contact resistivity more accurately. However, the normal lighting condition did not significantly affect the calculation of contact resistivity. In Table 1, the impact of the abovementioned uncertainty factors on the contact resistivity measurements are summarized.

Factors that were related with the formulation method and composition of silver paste, and the size of a crystalline silicon solar cell wafer, were also investigated. It was found that silver paste not only needs to be aged for a while to exhibit stabilized resistance measurements but that also the use of small silver particles adversely affects contact resistivity in the following two plausible ways: (1) residual stress induced poor contact formation due to the high volumetric shrinkage of the sintered silver electrodes, especially when the size of silver particles is close to a few tens of nanometers and below; and/or (2) poor contact formation thanks to the impeded flow of the molten glass frit to the surface of a crystalline silicon solar cell wafer during a high temperature sintering process.

The last factor to consider in resistance measurements is the size of a crystalline silicon solar cell wafer where specimens for the resistance measurements were prepared. As the size of a crystalline silicon solar cell wafer gets larger, the magnitude of bowing increases and hence, the different thermal contractions of the silver electrodes and crystalline silicon solar cell wafer leads to poor contact formation. Therefore, the size of a crystalline silicon solar cell wafer from which specimens for resistance measurements are prepared should be the same size of a crystalline silicon solar cell, in order to obtain accurate and realistic resistance measurements for the calculation of contact resistivity. Therefore, we have concluded that the findings presented in this study will be a good practical guide to those who are developing silver paste for a crystalline silicon solar cell by lessening their trials and errors.

\section{ACKNOWLEDGEMENT}

This work was supported by a Research Grant of Pukyong National University (C-D-2014-0241).

\section{REFERENCES}

1. Kim, M.-S., Chun, D.-M., Choi, J.-O., Lee, J.-C., Kim, K.-S., et al., "Room Temperature Deposition of $\mathrm{TiO}_{2}$ Using Nano Particle Deposition System (NPDS): Application to Dye-Sensitized Solar cell (DSSC),’ Int. J. Precis. Eng. Manuf., Vol. 12, No. 4, pp. 749-752, 2011.

2. Hwang, D. S., Lee, C. H., Lee, J. O., Jeon, C. Y., Lim, Y. B., et al., "Influences of Deposition Parameters on Micro-Crystalline Silicon Single Junction Cell Efficiency in Large-Area and High Rate Deposition,” Int. J. Precis. Eng. Manuf., Vol. 13, No. 7, pp. 11131116, 2012.

3. Seo, H., Ichida, D., Uchida, G., Kamatake, K., Itagaki, N., et al., "Analysis on the Photovoltaic Property of Si Quantum DotSensitized Solar Cells,” Int. J. Precis. Eng. Manuf., Vol. 15, No. 2, pp. 339-343, 2014. 
4. Bhandari, B., Poudel, S. R., Lee, K.-T., and Ahn, S.-H., "Mathematical Modeling of Hybrid Renewable Energy System: A Review on Small Hydro-Solar-Wind Power Generation," Int. J. Precis. Eng. Manuf.-Green Tech., Vol. 1, No. 2, pp. 157-173, 2014.

5. Bhandari, B., Lee, K.-T., Lee, G.-Y., Cho, Y.-M., and Ahn, S.-H., "Optimization of Hybrid Renewable Energy Power Systems: A Review,” Int. J. Precis. Eng. Manuf.-Green Tech., Vol. 2, No. 1, pp. 99-112, 2015.

6. Hilali M. M., Sridharan, S., Khadilkar, C., Shaikh, A., Rohatgi, A., et al., "Effect of Glass Frit Chemistry on the Physical and Electrical Properties of Thick-Film Ag Contacts for Silicon Solar Cells," Journal of Electronic Materials, Vol. 35, No. 11, pp. 2041-2047, 2006.

7. Jeon, S. J., Koo, S. M., and Hwang, S. A., "Optimization of Leadand Cadmium-Free Front Contact Silver Paste Formulation to Achieve High Fill Factors for Industrial Screen-Printed Si Solar Cells," Solar Energy Materials and Solar Cells, Vol. 93, No. 6, pp. 1103-1109, 2009.

8. Kim, D., Shim, S., Hwang, S., and Kim, H., "Electrical Properties of Screen Printed Silicon Solar Cell Dependent upon Thermophysical Behavior of Glass Frits in Ag Pastes," Japanese Journal of Applied Physics, Vol. 48, No. 5S2, Paper No. 05EC06, 2009.

9. Zhang, Y., Yang, Y., Zheng, J., Hua, W., and Chen, G., "Thermal Properties of Glass Frit and Effects on Si Solar Cells," Materials Chemistry and Physics, Vol. 114, No. 1, pp. 319-322, 2009.

10. Lee, E. J., Kim, D. S., and Lee, S. H., "Ni/Cu Metallization for Low-Cost High-Efficiency PERC Cells," Solar Energy Materials and Solar Cells, Vol. 74, No. 1, pp. 65-70, 2002.

11. Chaudhari, V. A. and Solanki, C. S., "A Novel Two Step Metallization of $\mathrm{Ni} / \mathrm{Cu}$ for Low Concentrator C-Si Solar Cells," Solar Energy Materials and Solar Cells, Vol. 94, No. 12, pp. 20942101, 2010.

12. Xu, C., Wang, J., Wang, M., Jin, H., Hao, Y., et al., "Reeves's Circular Transmission Line Model and Its Scope of Application to Extract Specific Contact Resistance," Solid-State Electron., Vol. 50, No. 5, pp. 843-847, 2006.

13. Lewis, L., Maaskant, P. P., and Corbett, B., "On the Specific Contact Resistance of Metal Contacts to p-Type GaN," Semiconductor Science and Technology, Vol. 21, No. 12, pp. 1738-1742, 2006.

14. Kato, H., Takeuchi, D., Tokuda, N., Umezawa, H., Okushi, H., et al., "Characterization of Specific Contact Resistance on Heavily Phosphorus-Doped Diamond Films," Diamond and Related Materials, Vol. 18, No. 5, pp. 782-785, 2009

15. Dobrzañski, L. A., Musztyfaga, M., Drygała, A., and Panek, P., "Investigation of the Screen Printed Contacts of Silicon Solar Cells Using Transmission Line Model," Journal of Achievements in Materials and Manufacturing Engineering, Vol. 41, No. 1-2, pp. 5765, 2010.
16. Zeng, F., Feng, Y., Liang, Z., and Shen, H., "Specific Contact Resistance Measurements on C-Si Solar Cells by Novel TLM Method," Proc. of the $38^{\text {th }}$ IEEE on Photovoltaic Specialists Conference, pp. 000509-000513, 2012.

17. Vinod, P. N., Chakravarty, B. C., Lal, M., Kumar, R., and Singh, S. N., "A Novel Method for the Determination of the Front Contact Resistance in Large Area Screen Printed Silicon Solar Cells," Semiconductor Science and Technology, Vol. 15, No. 3, pp. 286290,2000

18. Vinod, P. N., "Specific Contact Resistance Measurements of the Screen-Printed Ag Thick Film Contacts in the Silicon Solar Cells by Three-Point Probe Methodology and TLM Method," Journal of Materials Science: Materials in Electronics, Vol. 22, No. 9, pp. 1248-1257, 2011.

19. Vinod, P. N., "The Electrical and Microstructural Properties of Electroplated Screen-Printed Ag Metal Contacts in Crystalline Silicon Solar Cells," RSC Advances, Vol. 3, No. 33, pp. 1410614113, 2013.

20. Goetzberger, A., Knobloch, J., and Voss, B., "Crystalline Silicon Solar Cells,” $1^{\text {st }}$ Ed., John Wiley \& Sons Ltd., 1998.

21. Melczarsky, M., Garcia, G. G., Posthuma, N. E., Van Kerschaver, E., and Beaucarne, G., "Contact Resistance Measurement Technologies for Ag Thick-Film Screen-Printed Contacts to Solar Cells," Proc. of the $34^{\text {th }}$ IEEE on Photovoltaic Specialists Conference, pp. 960-963, 2009.

22. Dhara, S. and Bargava, P., "Influence of Nature and Amount of Dispersant on Rheology of Aged Aqueous Alumina Gelcasting Slurries," Journal of the American Ceramic Society, Vol. 88, No. 3, pp. 547-552, 2005.

23. Shin, D.-Y., Cha, Y.-K., Ryu, H.-H., and Kim, S.-H., "Impact of Effective Volume Ratio of a Dispersant to Silver Nano-Particles on Silicon Solar Cell Efficiency in Direct Ink-Jet Metallization," Journal of Micromechanics and Microengineering, Vol. 22, No. 11, Paper No. 115007, 2012. 